\title{
Double layering of a thermochemical plume in the upper mantle beneath Hawaii
}

\author{
Maxim D. Ballmer ${ }^{\mathrm{a}, *}$, Garrett Ito ${ }^{\mathrm{a}}$, Cecily J. Wolfe ${ }^{\mathrm{b}, \mathrm{c}}$, Sean C. Solomon ${ }^{\mathrm{c}, \mathrm{d}}$ \\ a Department of Geology and Geophysics, School of Ocean and Earth Sciences and Technology, University of Hawaii at Manoa, Honolulu, HI 96822, USA \\ ${ }^{\mathrm{b}}$ Hawaii Institute of Geophysics and Planetology, School of Ocean and Earth Sciences and Technology, University of Hawaii at Manoa, Honolulu, HI 96822, USA \\ c Department of Terrestrial Magnetism, Carnegie Institution of Washington, Washington, DC 20015, USA \\ d Lamont-Doherty Earth Observatory, Columbia University, Palisades, NY 10964, USA
}

\section{A R T I C L E I N F O}

\section{Article history:}

Received 2 December 2012

Received in revised form 6 May 2013

Accepted 14 June 2013

Available online $\mathrm{xxxx}$

Editor: Y. Ricard

\section{Keywords:}

intraplate volcanism

thermochemical mantle plume

seismic resolution test

Hawaii

hotspot

\begin{abstract}
A B S T R A C T
According to classical plume theory, purely thermal upwellings rise through the mantle, pond in a thin layer beneath the lithosphere, and generate hotspot volcanism. Neglected by this theory, however, are the dynamical effects of compositional heterogeneity carried by mantle plumes even though this heterogeneity has been commonly identified in sources of hotspot magmas. Numerical models predict that a hot, compositionally heterogeneous mantle plume containing a denser eclogite component tends to pool at $\sim 300-410 \mathrm{~km}$ depth before rising to feed a shallower sublithospheric layer. This double-layered structure of a thermochemical plume is more consistent with seismic tomographic images at Hawaii than the classical plume model. The thermochemical structure as well as time dependence of plume material rising from the deeper into the shallower layer can further account for long-term fluctuations in volcanic activity and asymmetry in bathymetry, seismic structure, and magma chemistry across the hotspot track, as are observed.
\end{abstract}

(c) 2013 Elsevier B.V. All rights reserved.

\section{Introduction}

Hotspots dominate volcanism interior to Earth's tectonic plates and are related to convective processes and chemical heterogeneity in the underlying mantle. The characteristics of the Hawaiian hotspot, in particular, have been key to the development of classical plume theory, a well-established paradigm for understanding the hotspot phenomenon (Morgan, 1972). According to this theory, a high-temperature, buoyant plume rises vertically from the base of the mantle to pond beneath the lithosphere in a 100-km-thick "pancake." The ascending plume supports a broad area of uplifted seafloor, known as the hotspot swell, and sustains localized decompression melting that feeds age-progressive volcanism on the overriding plate (Morgan, 1972; Sleep, 1990; Ribe and Christensen, 1994, 1999).

Regional seismic tomographic studies of the Hawaiian hotspot (Wolfe et al., 2009, 2011; Laske et al., 2011) have called aspects of this model into question. Whereas anomalously low seismic velocities found in the lower and upper mantle confirm the presence of a high-temperature mantle plume, the upper-mantle low-velocity anomaly appears to have a greater vertical extent and is laterally more asymmetric about the island chain than predicted by the classical plume theory (Figs. 1-2). In particular, the station-

\footnotetext{
* Corresponding author.

E-mail address: ballmer@hawaii.edu (M.D. Ballmer).
}

averaged, body-wave travel-time residuals across the Hawaiian swell are larger than would be expected from a $\sim 100-\mathrm{km}$-thick pancake on the basis of independent surface-wave constraints (Wolfe et al., 2009, 2011; Laske et al., 2011). Moreover, episodic, high-amplitude variations in volcanic flux along the chain are evident in the geologic record for the past $\sim 85 \mathrm{Myr}$ (van Ark and Lin, 2004; Vidal and Bonneville, 2004). These characteristics of the Hawaiian hotspot suggest that plume upwelling is more complex in space and time than portrayed by the classical model.

The classical plume theory emphasizes thermal buoyancy of typical mantle material, or peridotite, to drive upwelling. However, there is growing petrologic and geochemical evidence, especially at Hawaii, for the presence of eclogite in the magma source region (Hauri, 1996; Farnetani and Samuel, 2005; Sobolev et al., 2005, 2007; Herzberg, 2011; Jackson et al., 2012; Pietruszka et al., 2013), thought to originate from subducted oceanic crust and to be entrained by upwelling flow in the lower mantle (e.g., Deschamps et al., 2011). Because eclogite is denser than peridotite throughout the upper mantle and most of the lower mantle (Hirose, 2002; Aoki and Takahashi, 2004), the ascent of plumes containing both peridotite and eclogite will be influenced by a competition between non-diffusive, negative chemical buoyancy and diffusive, positive thermal buoyancy (e.g., Davaille, 1999). Compared with classical thermal plumes, such thermochemical plumes therefore display much more complex dynamics. For example, dense materials carried by the plume can induce large fluctuations in ascent 


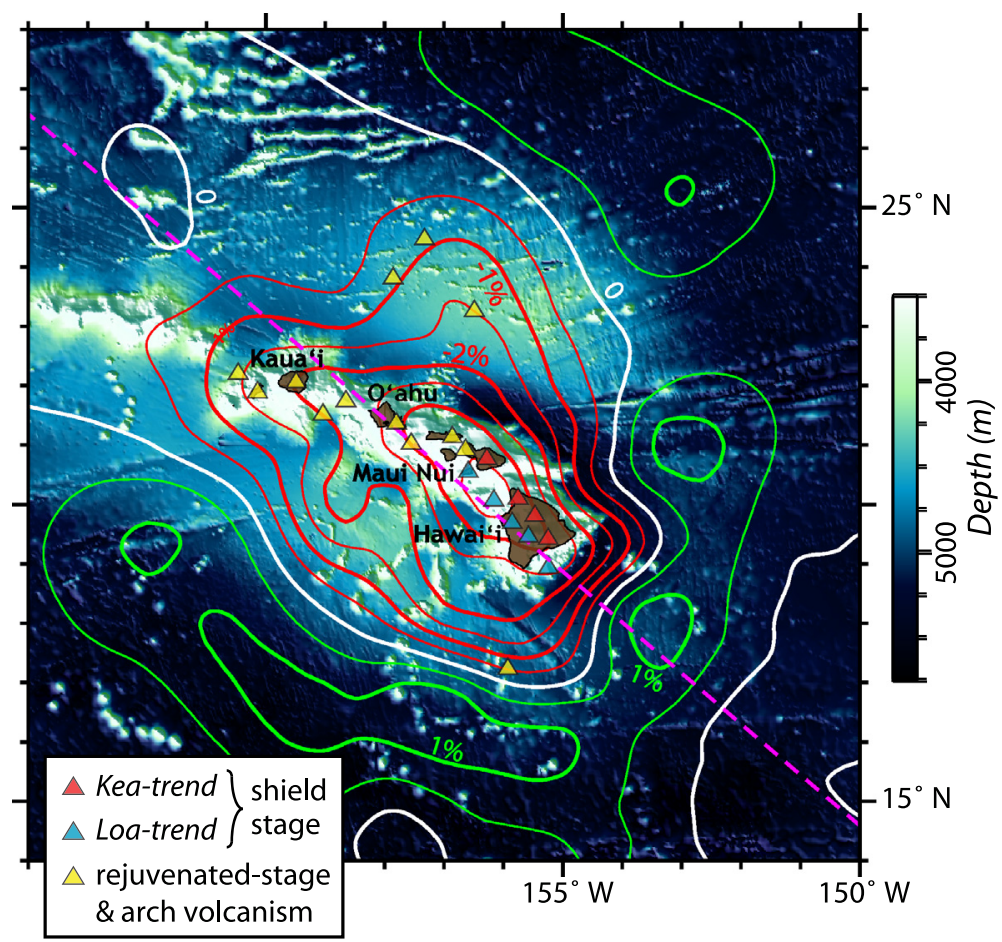

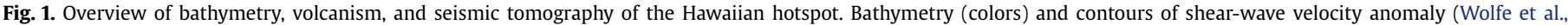

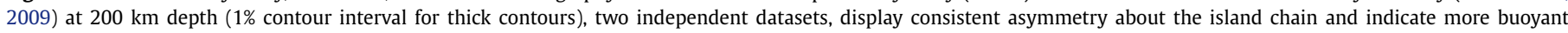

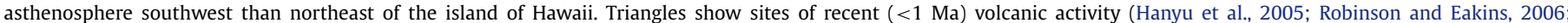

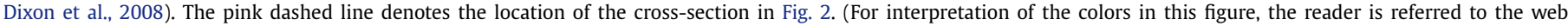
version of this article.)

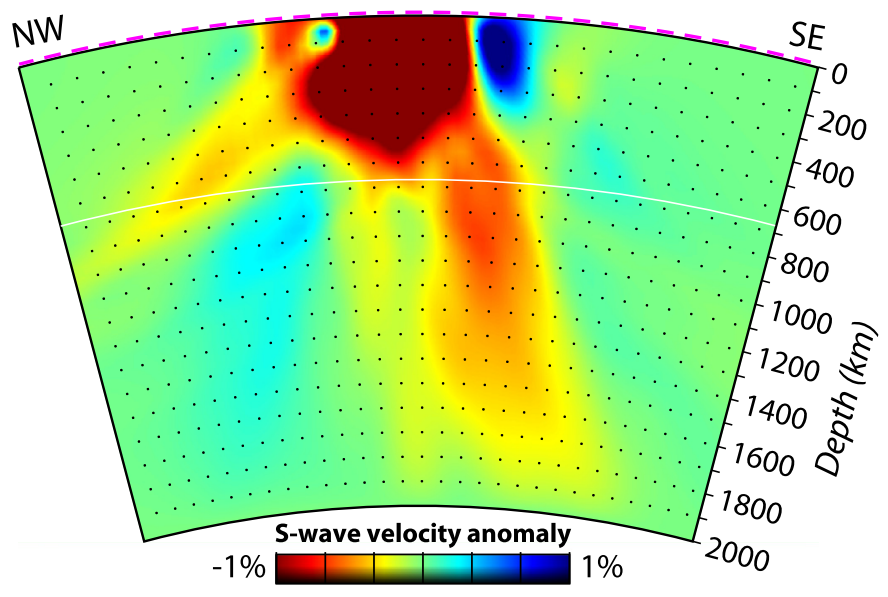

Fig. 2. Vertical cross-section of shear-wave velocity beneath Hawaii (Wolfe et al., 2009) along a northwest-southeast-trending profile (denoted by the pink dashed line in Fig. 1). (For interpretation of the colors in this figure, the reader is referred to the web version of this article.)

rate and volume flux as well as asymmetric behavior (Farnetani and Samuel, 2005; Lin and van Keken, 2005; Samuel and Bercovici, 2006; Kumagai et al., 2008; Sobolev et al., 2011). The effects of phase changes can further modify this behavior, for example, by affecting the rise of plumes through the boundary between the lower and upper mantle at $660 \mathrm{~km}$ depth (Farnetani and Samuel, 2005; Tosi and Yuen, 2011). Moreover, phase changes in the depth range of about $300-410 \mathrm{~km}$ can further increase the compositional density excess of eclogitic material (Aoki and Takahashi, 2004), an effect that is should strongly influence the dynamics of thermochemical plumes, but one that has yet to be explored.

In order to study the dynamics and melting behavior of a thermochemical plume in the upper mantle beneath the Hawaiian hotspot and to address the enigmatic seismic structure imaged we have conducted three-dimensional numerical simulations. We show that the interaction of a thermochemical plume with phase changes can give rise to pooling of plume material in the mid upper mantle. Strong pulsations of plume flow out of this layer can lead to temporal and spatial variations in the volume flux and composition of hotspot magmatism, respectively. The behavior of this double-layered, thermochemical plume indeed permits a range of geophysical, geochemical, and geological observations to be addressed.

\section{Methods and model description}

The numerical simulations were produced using an extended version (see Section 2.1) of the finite element code Citcom (Moresi et al., 1996). The model domain of the numerical experiment was $5280 \mathrm{~km}$ long, $3300 \mathrm{~km}$ wide, and $660 \mathrm{~km}$ deep. It was divided into $768 \times 512 \times 96$ finite elements with rectangular faces and with the smallest elements (i.e., highest resolution) about $4.5 \times 4.5 \times 4.5 \mathrm{~km}$ in dimensions and located in the asthenosphere near the hotspot. A velocity condition of $80 \mathrm{~km} / \mathrm{Myr}$ was applied at the top boundary to simulate Pacific plate motion. Accordingly, the boundaries at the front and back were open to inflow and outflow, respectively. The other boundaries were closed except for a small circular area of radius $360 \mathrm{~km}$ around the base of the plume (which is centered $3135 \mathrm{~km}$ from the front boundary and $1650 \mathrm{~km}$ from the sides) to allow influx of plume material. At the bottom boundary, the plume's thermal anomaly was specified to decrease as a Gaussian function of radial distance from the center, with a peak amplitude of $300 \mathrm{~K}$ and a half width of $75 \mathrm{~km}$.

The modeled plume contains eclogite within a radial distance $r_{P}$ of its center, and the eclogite makes up 15\% of the mass of this portion of the plume (cf. Sobolev et al., 2005). Outside of $r_{P}$, the ambient mantle was taken to contain no eclogite, but instead $15 \%$ 
Table 1

Governing parameters in the geodynamical models.

\begin{tabular}{|c|c|c|}
\hline Parameter & Description & Value \\
\hline$c_{d r y}$ & water content below which peridotite behaves like dry peridotite & $6(\mathrm{ppm})$ \\
\hline$c_{0}$ & reference water content in hydrous peridotite & $300(\mathrm{ppm})$ \\
\hline$c_{P}$ & specific heat capacity & $1250\left(\mathrm{~J} \mathrm{~kg}^{-1} \mathrm{~K}^{-1}\right)$ \\
\hline$D_{\mathrm{H}_{2} \mathrm{O}}$ & water partitioning coefficient & 0.01 \\
\hline$E^{*}$ & activation energy & $3 \times 10^{-5}(\mathrm{~J} / \mathrm{mol})$ \\
\hline$g$ & gravitational acceleration & $9.8\left(\mathrm{~m} / \mathrm{s}^{2}\right)$ \\
\hline$L$ & latent heat of melt & $5.6 \times 10^{5}(\mathrm{~J} / \mathrm{kg})$ \\
\hline$r_{\text {plume }}$ & half width of plume thermal anomaly & $75(\mathrm{~km})$ \\
\hline$T_{0}$ & reference temperature & $1350\left({ }^{\circ} \mathrm{C}\right)$ \\
\hline$V^{*}$ & activation volume & $5 \times 10^{-6}\left(\mathrm{~m}^{3} / \mathrm{mol}\right)$ \\
\hline$\alpha$ & thermal expansivity & $3 \times 10^{-5}\left(\mathrm{~K}^{-1}\right)$ \\
\hline$\gamma$ & adiabatic gradient & $0.3(\mathrm{~K} / \mathrm{km})$ \\
\hline$\Delta T_{\text {plume }}$ & plume peak thermal anomaly & $300(\mathrm{~K})$ \\
\hline$\Delta \rho_{E C L}$ & excess density of eclogite & $110-220\left(\mathrm{~kg} / \mathrm{m}^{3}\right)$ (see text) \\
\hline$\Delta \rho_{F}$ & density change with depletion & $-165\left(\mathrm{~kg} / \mathrm{m}^{3}\right)$ \\
\hline$\zeta$ & melt lubrication exponent & 40 \\
\hline$\eta_{\text {eff }}$ & effective asthenospheric viscosity & $1.8 \times 10^{19}($ Pa s $)$ \\
\hline$\kappa$ & thermal diffusivity & $10^{-6}\left(\mathrm{~m}^{2} / \mathrm{s}\right)$ \\
\hline$\xi$ & depletion stiffening coefficient & 310.6383 \\
\hline$\rho_{0}$ & reference density & $3300\left(\mathrm{~kg} / \mathrm{m}^{3}\right)$ \\
\hline$\rho_{M}$ & density of melt & $2800\left(\mathrm{~kg} / \mathrm{m}^{3}\right)$ \\
\hline$\varphi_{C}$ & critical porosity in peridotite & 0.004 \\
\hline$\varphi_{C, P Y X}$ & critical porosity in pyroxenite & 0.1 \\
\hline$\varphi_{R}$ & residual porosity in peridotite & 0.004 \\
\hline$\varphi_{R, P Y X}$ & residual porosity in pyroxenite & 0.05 \\
\hline
\end{tabular}

of a refractory lithology that does not melt beneath the hotspot (cf. Stracke et al., 2011). The remaining $85 \%$ of the mantle both within and beyond $r_{P}$ was taken to be peridotite, of which $20 \%$ was hydrous peridotite with a water content of 300 ppm by weight, and $65 \%$ was dry peridotite. We considered two models with different values of $r_{P}: 90 \mathrm{~km}$ in case A and $100 \mathrm{~km}$ in case B. Accordingly, the excess temperature at the distance $r_{P}$ from the deep plume axis is $\sim 110.4 \mathrm{~K}$ in case $\mathrm{A}$ and $\sim 87.3 \mathrm{~K}$ in case $\mathrm{B}$, and only the portion of the plume core with higher excess temperatures is assumed to contain eclogite.

\subsection{Numerical approach}

Compared with the original, parallelized version of Citcom (Moresi et al., 1996), the numerical code has been extended to allow modeling of the dynamics and melting of thermochemical plumes. The extended Boussinesq approximations have been used to solve the equations of conservation of mass, momentum, and energy. Numerical particles have been added to track composition (van Hunen et al., 2005). We have further developed schemes for melting the various components (i.e., hydrous peridotite, dry peridotite, eclogite, and pyroxenite), as well as parameterizations of the effects of depletion in these components on density and rheology (described below). The related strong, time-dependent feedbacks required the application of a second-order Runge-Kutta predictor-corrector scheme for time integration of the aforementioned equations.

\subsection{Melting parameterization}

The mantle source was assumed to be composed of a fine-scale mixture of the distinct lithological components, each with a different melting behavior. For eclogite, we used the melting parameterization derived from the batch melting experiments of Yasuda et al. (1994), and we assumed that eclogitic melts react instantly with ambient lherzolites in a 1-to-1 fashion to form silica-free garnet pyroxenites (Yaxley and Green, 1998; Sobolev et al., 2005, 2007). Eclogite melting and hybridization of the ambient mantle were taken to consume and release equivalent amounts of latent heat, respectively. Pyroxenites were assumed to melt at a much shallower depth than eclogites, according to the experiments of Pertermann and Hirschmann (2003). As soon as the volume fraction (porosity) of pyroxenite melts relative to the pyroxenite part of the mantle $\varphi_{P Y X}$ exceeded a critical threshold of $\varphi_{C, P Y X}=10 \%$, about half of the pyroxenitic melts were extracted instantaneously to leave a residual porosity of $\varphi_{R, P Y X}=5 \%$. We capped melting of eclogite and pyroxenite at degrees of melting of $60 \%$ and $55 \%$, respectively (Sobolev et al., 2005, 2011). Peridotite was assumed to melt dynamically according to the parameterization of Hirschmann (2000), with critical and residual porosities in the peridotite part of the mantle $\varphi_{C}=\varphi_{R}=0.4 \%$. Relative to dry peridotite, the solidus of hydrous peridotite was reduced as a function of the water content in the liquid $c_{L}$ [i.e., by $43 c_{L} \mathrm{~K} / \mathrm{wt} \%$ (Katz et al., 2003)] using

$c_{L}=\frac{c}{D_{\mathrm{H}_{2} \mathrm{O}}}=\frac{c_{0}}{F_{H P}+D_{\mathrm{H}_{2} \mathrm{O}}\left(1-F_{H P}\right)}$

for $F_{H P}<\varphi_{C}$, and

$c_{L}=\frac{c}{D_{\mathrm{H}_{2} \mathrm{O}}}=c_{0} \frac{\left(1-\frac{F_{H P}-\varphi_{C}}{1-\varphi_{C}}\right)^{\frac{1}{\varphi_{C}\left(1-D_{\mathrm{H}_{2} \mathrm{O}}\right)+D_{\mathrm{H}_{2} \mathrm{O}}}-1}}{\varphi_{\mathrm{C}}+D_{\mathrm{H}_{2} \mathrm{O}}\left(1-\varphi_{C}\right)}$

for $F_{H P} \geqslant \varphi_{C}$, where $c_{0}$ is the starting water content in hydrous peridotite, $c$ is the water content in hydrous peridotite, $F_{H P}$ is the melt depletion of hydrous peridotite, and $\mathrm{D}_{\mathrm{H}_{2} \mathrm{O}}$ is the bulk partitioning coefficient of water (Zou, 1998). The values of the above parameters are given in Table 1.

\subsection{Buoyancy parameterization}

Melt retention, temperature, the abundance of eclogite, and depletion in peridotite were assumed to control the density of the mantle:

$$
\begin{aligned}
\rho= & \rho_{0}-\alpha\left(T-T_{0}\right)+\left(\rho_{M}-\rho_{0}\right) \varphi \\
& +\Delta \rho_{F}\left(F_{D P} \Phi_{D P}+F_{H P} \Phi_{H P}\right)+\Delta \rho_{E C L} \Phi_{E C L}
\end{aligned}
$$

where

$\varphi=\varphi_{P Y X} \Phi_{P Y X}+\varphi_{D P} \Phi_{D P}+\varphi_{H P} \Phi_{H P}$ 


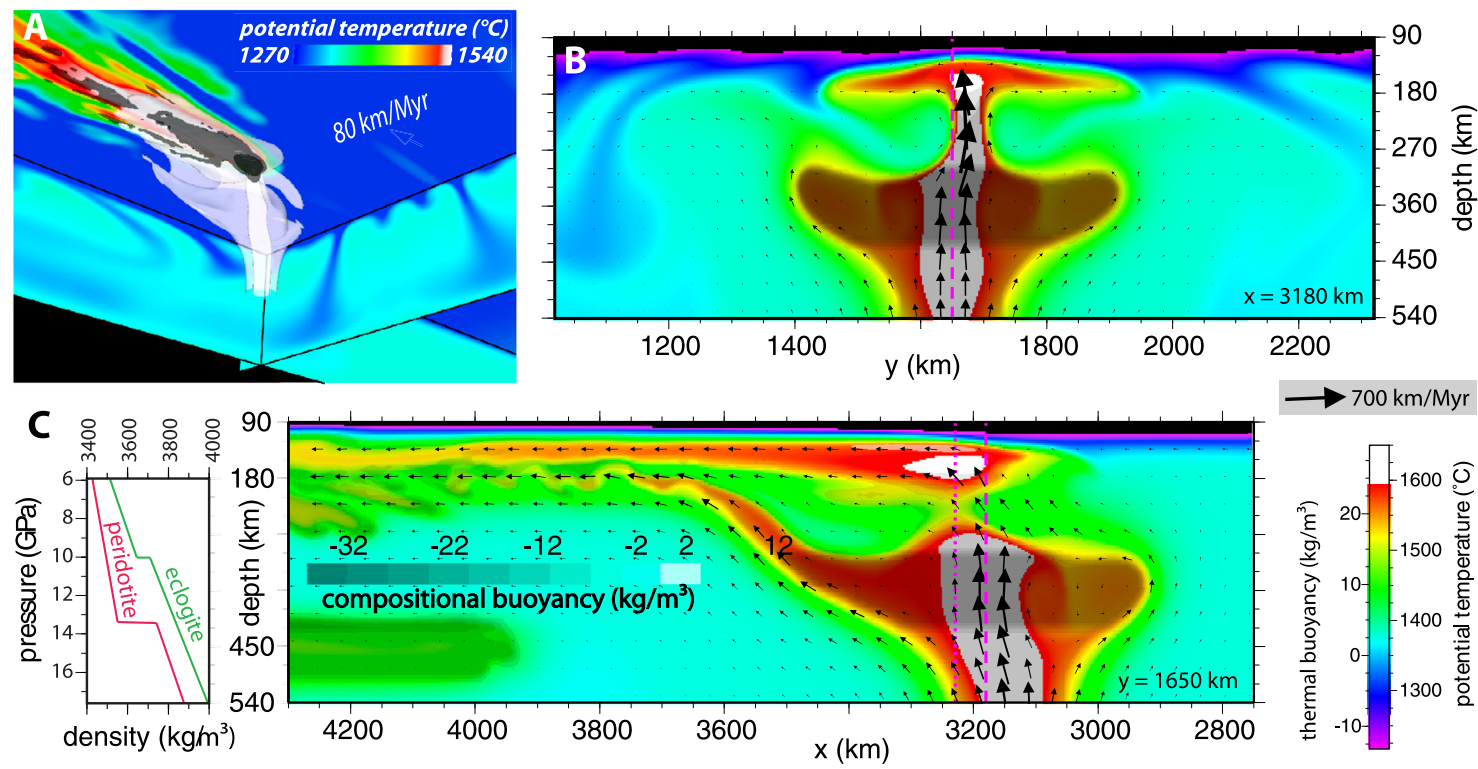

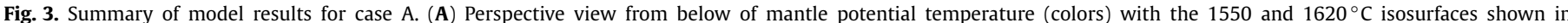

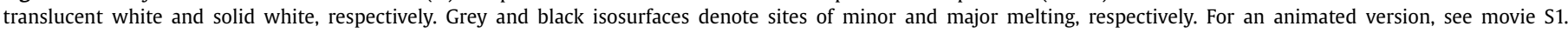

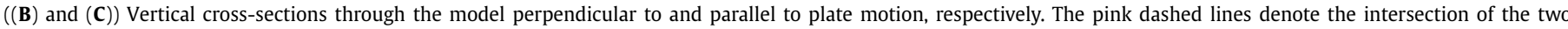

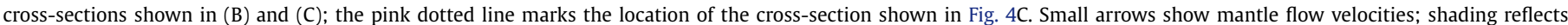

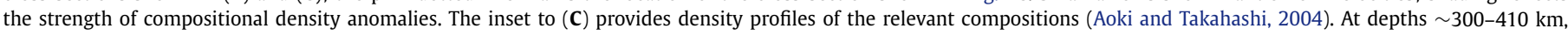
the excess density of eclogite peaks and hot material accumulates to form a deep eclogitic pool (DEP).

and subscripts PYX, ECL, HP, and DP refer to the pyroxenite, eclogite, and hydrous and dry peridotite components, respectively. Regarding the other variables, $T$ is temperature, $T_{0}$ reference temperature, $\rho$ density, $\rho_{0}$ reference density, $\alpha$ thermal expansivity, $\Phi_{X X}$ volume fraction of a component, $\varphi_{X X}$ porosity in a component, $\varphi$ bulk porosity, $F_{X X}$ depletion of a component, $\rho_{M}$ density of melt, and $\triangle \rho_{E C L}$ excess density of solid eclogite. Depletion in dry and hydrous peridotite affects density, as heavy minerals and oxides are preferentially consumed during melting (Schutt and Lesher, 2006), so $\Delta \rho_{F}$ is the density reduction from depletion. The excess density of solid eclogite $\Delta \rho_{E C L}$ was fixed at $220 \mathrm{~kg} / \mathrm{m}^{3}$ in the depth range 300 to $410 \mathrm{~km}$ and $110 \mathrm{~kg} / \mathrm{m}^{3}$ elsewhere (Aoki and Takahashi, 2004).

\subsection{Rheology parameterization}

The effects of composition on rheology were also taken into account (in addition to those of temperature and depth). Retained melt lubricates mantle rocks (Kohlstedt and Zimmerman, 1996), but stiffening related to dehydration of hydrous peridotite (Hirth and Kohlstedt, 1996) is thought to be dominant (Karato, 1986). A Newtonian rheology with an activation energy that is consistent with experimental constraints (Karato and Wu, 1993) has been applied:

$\eta=\eta_{m} \exp \left(\frac{E^{*}+\rho_{m} g z V^{*}}{R T}-\frac{E^{*}}{R T_{m}}\right) \frac{\left[\left(c-c_{d r y}\right) \frac{\xi}{\xi-1}\right]^{\Phi_{H P}}}{\exp (\zeta \varphi)}$

where $\eta$ is viscosity, $\eta_{m}$ reference viscosity, $z$ depth, $g$ gravitational acceleration, $\zeta$ melt lubrication exponent, $V^{*}$ activation volume, $E^{*}$ activation energy, $R$ ideal gas constant, and $c_{d r y}$ the water content below which peridotite behaves as dry peridotite (values given in Table 1). The depletion stiffening factor $\xi$ was scaled such that viscosity of a peridotite that is dehydrated from $c=100 \mathrm{ppm}$ by weight to $c \leqslant c_{d r y}$ increases by a factor of 100 (Hirth and Kohlstedt, 1996). The reference viscosity $\eta_{m}$ used translates into an effective asthenospheric viscosity (far from the hotspot) of $\eta_{\text {eff }} \approx$ $1.8 \times 10^{19}$ Pas.

\section{Thermochemical plume dynamics in the upper mantle}

Our models were designed to simulate the Hawaiian plume, and their predictions are in general agreement with the most robust geological and geophysical constraints (also see Supplementary material). The modeled plume is up to $300 \mathrm{~K}$ hotter than the ambient mantle (cf. Herzberg et al., 2007), and its hottest core carries a fine-scale mixture of $15 \%$ eclogite and $85 \%$ peridotite. Eclogite is denser than ambient-mantle peridotite throughout the upper mantle, thereby slowing down and widening the thermochemical plume compared with an equally hot classical thermal plume. The thermochemical plume sustains (i.e., in case A) a volcanic flux of $\sim 175,000 \mathrm{~km}^{3} / \mathrm{Myr}$ (cf. van Ark and Lin, 2004; Robinson and Eakins, 2006) and supports a hotspot swell of height $\sim 1 \mathrm{~km}$ and width $\sim 1200 \mathrm{~km}$ (cf. Wessel, 1993; Crosby and McKenzie, 2009).

Model results show that the doubling of the density difference between eclogite and peridotite in the depth range $\sim 300-410 \mathrm{~km}$ has a major effect on the dynamics of the upwelling plume (Fig. 3C; Aoki and Takahashi, 2004). Once the hot and initially positively buoyant, eclogite-bearing plume core rises through the olivine-wadsleyite phase transition at $410 \mathrm{~km}$ depth, it becomes slightly negatively buoyant (Fig. 4). Accordingly, as material continues to rise through this phase transition from below, it accumulates above 410 and spreads laterally in the mid upper mantle to form a deep eclogitic pool (DEP; Figs. 3-4). The warm eclogitebarren material that initially surrounded the eclogitic core in the deep plume conduit rises and becomes deflected up and around the DEP, wrapping it as a warm, buoyant sheath. This buoyant sheath restricts extensive lateral spreading of the DEP and, together with the underlying buoyant plume, dynamically supports the excess weight of the DEP.

The flux of plume material rising into the base of the DEP becomes approximately balanced by outflow, with most such outflow through the roof of the DEP and only a small fraction leaking out of its trailing edge (i.e., "downwind" in the ambient flow driven by plate motion). When the material rising out of the DEP crosses the 300-km-deep coesite-stishovite phase transition 

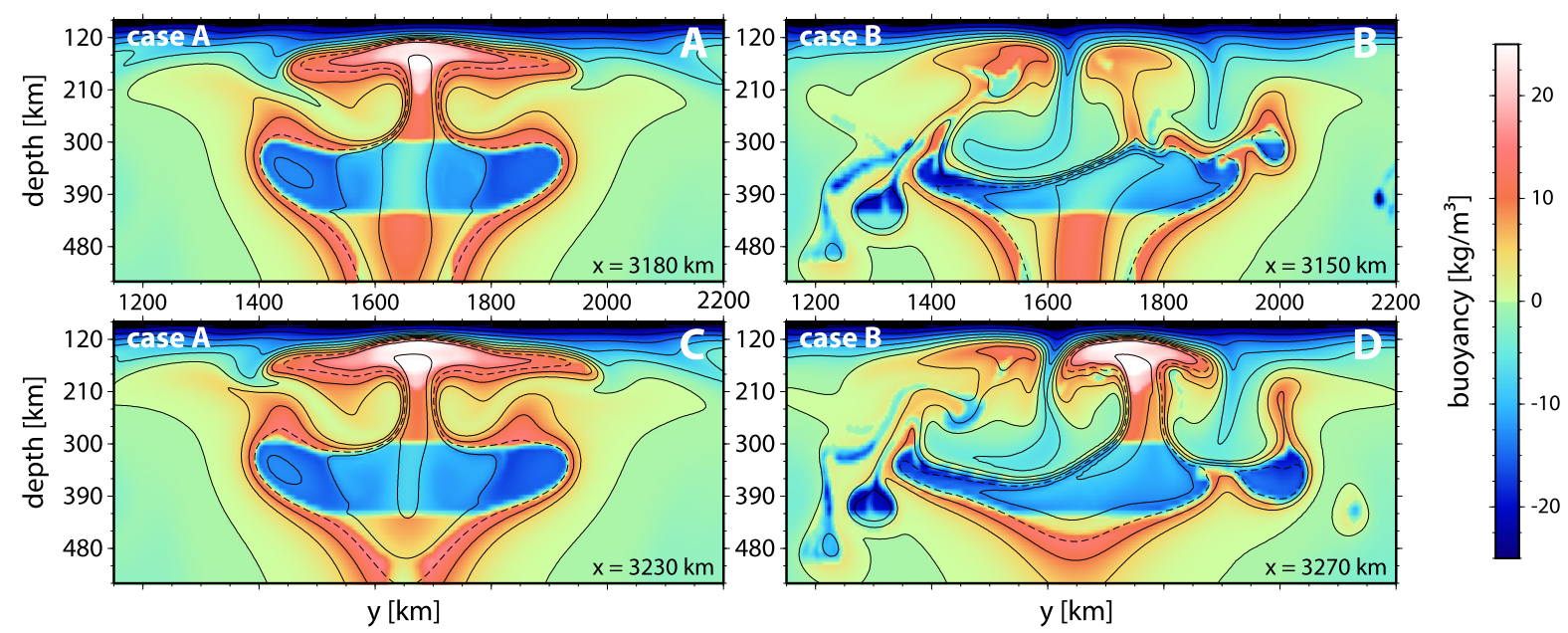

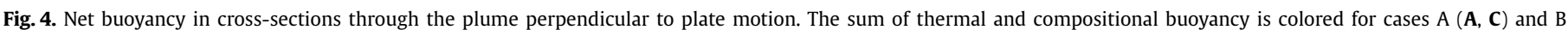

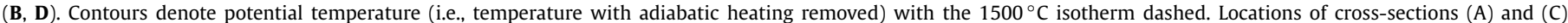

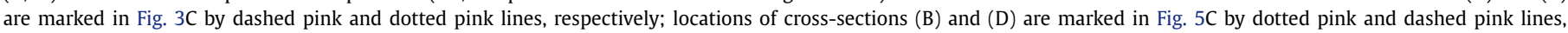
respectively. (For interpretation of the colors in this figure, the reader is referred to the web version of this article.)
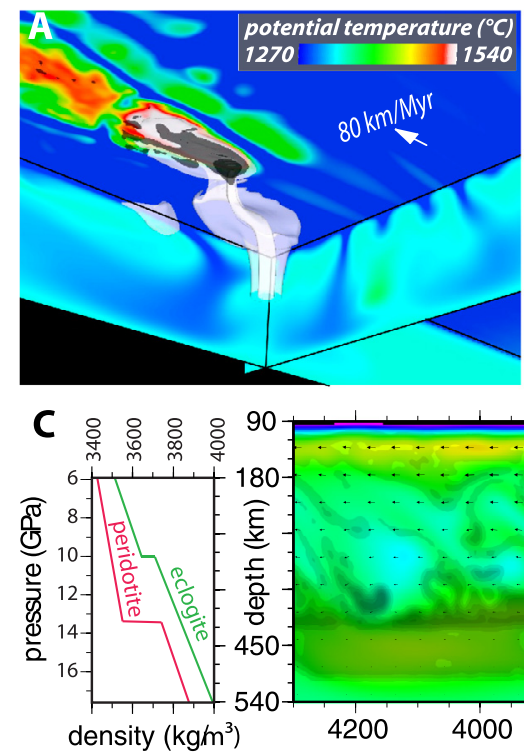

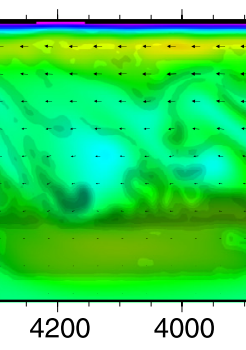

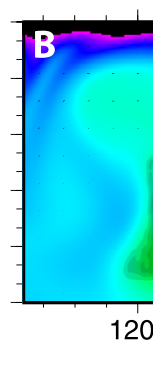
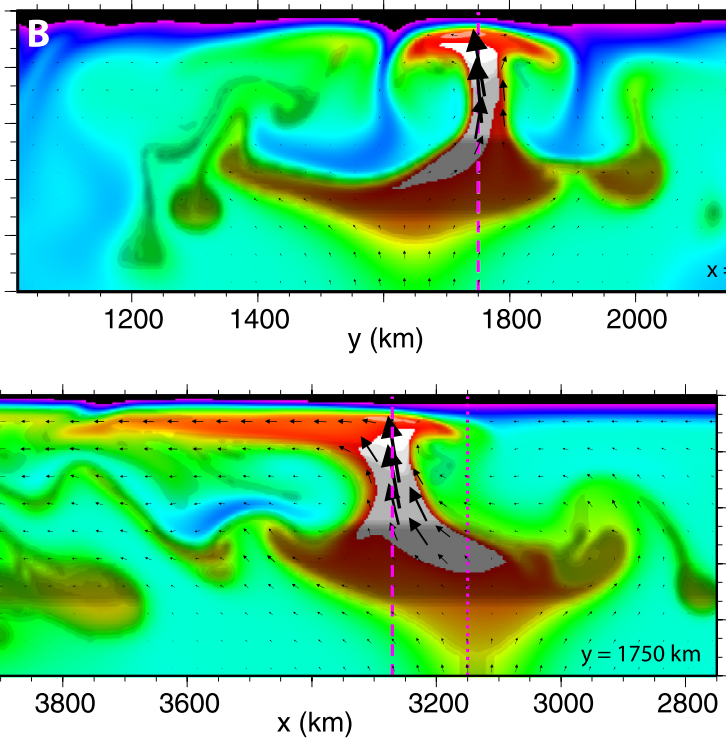

90

$-180$ $-270 \frac{\widehat{\xi}}{\frac{F}{5}}$
$-360 \frac{\overline{0}}{\frac{0}{0}}$ 450 540

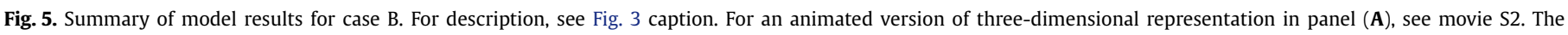

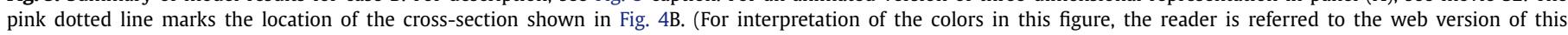
article.)

in eclogite, it regains a positive net buoyancy (Fig. 4). This positive buoyancy creates a positive feedback, in which the material rises more quickly and draws more material from below. At depths of about $250-150 \mathrm{~km}$, upwelling is reinforced further by melting of eclogite and the assumed instantaneous reaction of eclogitic melts with peridotite to form pyroxenite. Since the density of pyroxenite is not expected to differ markedly from that of peridotite, this process effectively removes the negative compositional buoyancy intrinsic to the plume core (shading in Figs. 3B-C, 5B-C). Consequently, the shallow upwelling behaves similar to that of a classical thermal plume. It is narrower than the underlying DEP and thermochemical plume conduit, and when it encounters the base of the lithosphere, it deflects into a thin $(<100 \mathrm{~km})$ thermal pancake, which supports the hotspot swell.

Near the deflection point, decompression melting is most voluminous and expected to feed hotspot volcanism. In terms of its flux and geographic age progression, the predicted volcanism agrees well with the Hawaiian shield stage (Supplementary material). The high isobaric melt productivity of mafic materials in the simulations causes the pyroxenite-derived lavas to compose the major volume fraction, $X_{P X}=80-90 \%$, of the magmas produced. This prediction is high compared with recent estimates for Hawaii, i.e., $X_{P X}=30-60 \%$ (Sobolev et al., 2005). This discrepancy could be indicative of lower eclogite contents in the most central Hawaiian plume core (e.g., $\leqslant 30 \mathrm{~km}$ from the axis), which melts most extensively beneath the hotspot, than modeled. In such an alternative scenario, the dynamics and geometry of the DEP are expected to be only marginally affected as long as the material surrounding the most central core (i.e., radial distances from $\sim 30 \mathrm{~km}$ to 90-100 km), which predominantly feeds inflation of the flanks of the DEP, contains $\sim 15 \%$ eclogite. However, we note that the predicted $X_{P X}$ values are upper bounds: melt-melt and melt-solid interactions, not simulated here, would tend to increase the effective melt productivity (and decrease the solidus temperature) 


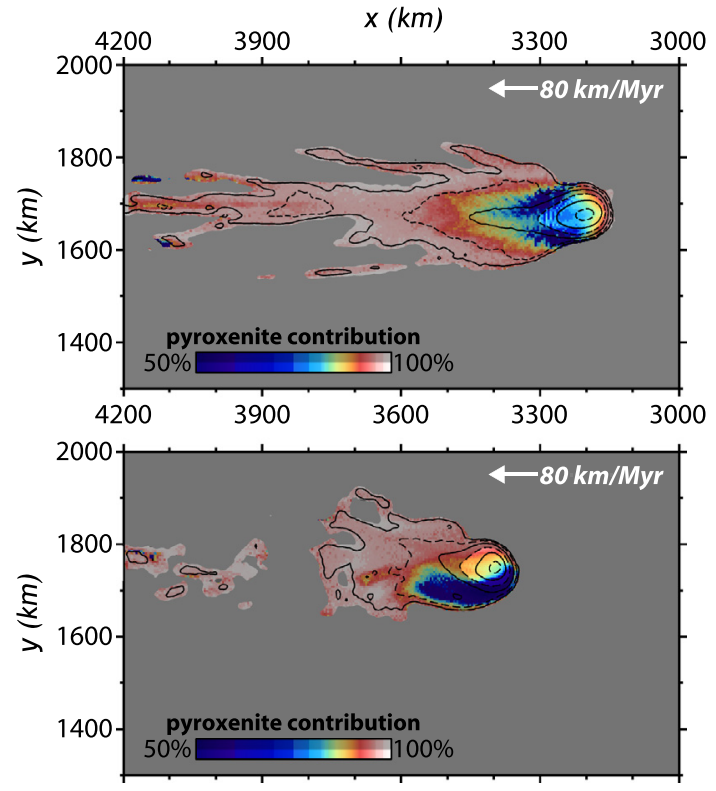

Fig. 6. Map views of predicted geographical distribution of volcanism. Contribution of pyroxenite-derived lavas to volcanism $X_{P X}$ (colors) and volcanic flux (solid contours $0.1,1$, and $10 \mathrm{~km}^{3} \mathrm{~km}^{-2} \mathrm{Myr}^{-1}$ from outside to inside) in a snapshot of (A) quasi steady-state case A and of (B) time-dependent case B. Minor volcanism (shaded) can occur well away from the hotspot, consistent with secondary Hawaiian volcanism. Predicted volcanic fluxes are upper bounds inasmuch as magmatic underplating is ignored. $X_{P X}$ for predicted shield-stage volcanism (not shaded) is near symmetric in case A (A) but strongly asymmetric about an axis parallel to plate motion in case B (B). (For interpretation of the colors in this figure, the reader is referred to the web version of this article.)

of peridotite relative to that of pyroxenite (Mallik and Dasgupta, 2012). Small adjustments in melt productivity and solidus temperature would indeed substantially reduce $X_{P X}$, as degrees of melting of peridotite in our models are limited by latent heat consumption during pyroxenite melting (cf. Katz and Rudge, 2011).

Additional decompression melting well away from the hotspot occurs above the upwelling material around the periphery of the DEP and as a result of small-scale convection within the shallow pancake (cf. Ballmer et al., 2011). The predicted small flux of this melting and its widespread geographic distribution agrees well with observed occurrences of rejuvenated-stage (Dixon et al., 2008) and arch volcanism (Hanyu et al., 2005) (Figs. 1 versus 6). The predicted difference in origin for the rejuvenated-stage and arch volcanism (i.e., from the plume outskirts) versus shield-stage volcanism (i.e., from the plume core) is consistent with geochemical evidence that these two forms of volcanism have distinct source materials (Yang et al., 2003; Hanyu et al., 2005; Fekiacova et al., 2007; Dixon et al., 2008).

Our models further predict asymmetries in upper-mantle thermochemical structure. The rise of the hottest plume-core material through the DEP is driven by an internal pressure gradient between the deep plume conduit feeding its base (high pressure) and the shallow plume drawing material out of its roof (low pressure). This pressure gradient overcomes the negative buoyancy intrinsic to the DEP material (Fig. 4) and drives material upward but not necessarily vertically, as the pressure field in the DEP is also influenced by ambient-mantle downwellings [from small-scale sublithospheric convection (Ballmer et al., 2011)] that compete with the rising plume outskirt material to shape the sides of the DEP. The result is asymmetric convection in the DEP, a tilted plume conduit above, and a bilaterally asymmetric thermal structure in the shallow pancake (Figs. 3B, 4, 5B, 7). These model predictions are consistent with observations of asymmetries in mantle seismic velocity (Wolfe et al., 2009, 2011; Laske et al., 2011) and seafloor bathymetry that both indicate more buoyant asthenosphere southwest than northeast of the island of Hawaii (Fig. 1).

The time-dependent behavior of our thermochemical plume models is sensitive to the distribution of eclogitic material in the deep plume stem. In case $A$, for which the radius of the eclogitebearing part of the plume stem is $90 \mathrm{~km}$, upwelling is nearly steady. In contrast, in case B, for which eclogitic material extends outward to just a slightly larger radius of $100 \mathrm{~km}$, upwelling is strongly time-dependent (movies S1 versus S2). On its less hot sides, the DEP in case B is denser and supported by a thinner outer sheath of warm, eclogite-barren material (Fig. 4). The DEP is less well confined and hence wider than in case A. Flow out of the roof of such a less stable DEP (as governed by the positive feedback mechanisms related to the coesite-stishovite phase transition) cannot be steadily sustained by plume ascent from below. Any such outflow intermittently drains the hottest core of the DEP, thereby reducing its average density. The resulting fluctuations in average DEP density, in combination with ambient-mantle convection (Fig. 5B), cause the DEP and shallow plume to pulse and wobble. Consequently, the rise of material out of the DEP changes in flux, eclogite content, and location relative to the lower mantle.

Such a temporal variability of plume behavior can account for some of the large fluctuations in magmatic flux indicated by variations in crustal thickness along the Hawaiian chain (van Ark and Lin, 2004). In case B, hotspot volcanic flux changes by $50-100 \%$ on timescales of $\sim 10 \mathrm{Myr}$ (Fig. 8 ; movies S2, S3). Fig. 8 shows that the amplitudes of these variations are similar to those documented, with the predicted spacing between the major peaks (i.e., 8.4-14.3 Myr) bracketed by those measured (i.e., 8.3-17.4 Myr) (van Ark and Lin, 2004). We note that this is one example calculation, and we have yet to explore the range of parameters that control the pulsations. We further emphasize that the predicted variations arise entirely out of the dynamics of thermochemical convection in the upper mantle, not from any fluctuations below $410 \mathrm{~km}$ depth. Any thermochemical plume pulsations rising out of the lower mantle are likely to operate on longer timescales $(\geqslant 30-50 \mathrm{Myr}$, Lin and van Keken, 2005) and would be superimposed on those rising out of the DEP.

The predictions for case $\mathrm{B}$ also have important implications for the geochemical distinction between the two subchains of the youngest Hawaiian volcanoes, the so-called Loa and Kea trends (Fig. 1) (Abouchami et al., 2005; Greene et al., 2010; Huang et al., 2011; Weis et al., 2011). Variations in the form and position of the upwelling plume above the DEP cause the drainage pattern of the DEP to be episodically strongly asymmetric in case B; material predominantly rises out of the DEP from where it has accumulated, and not necessarily from directly above the deep plume conduit (Fig. 5B; movie S2). Such an asymmetric drainage ultimately affects the thermal structure (Figs. 5, 7) and the distribution of pyroxenite in the melting zone. The associated asymmetry predicted in the geographical expression of pyroxenite-derived versus peridotitederived lavas $X_{P X}$ (Fig. 6) is consistent with geochemical evidence for a stronger pyroxenite-source signature along the Loa side of the Hawaiian chain than along the Kea side (Sobolev et al., 2005; Greene et al., 2010; Herzberg, 2011). Bianco et al. (2011) further demonstrate that such geographical variations in $X_{P X}$ would be expressed as subparallel trends in ${ }^{208} \mathrm{~Pb} /{ }^{204} \mathrm{~Pb}$ versus ${ }^{206} \mathrm{~Pb} /{ }^{204} \mathrm{~Pb}$, which is a characteristic criterion used to distinguish Loa versus Kea compositions (Abouchami et al., 2005). Thus, the geochemical difference between Loa and Kea lavas may be related to an asymmetric rise of the hottest eclogite-bearing plume core through the upper mantle rather than to a bilateral asymmetry of the deep plume conduit with distinct materials on the two sides (cf. Abouchami et al., 2005; Farnetani and Hofmann, 2009; Huang et al., 2011; Weis et al., 2011). 


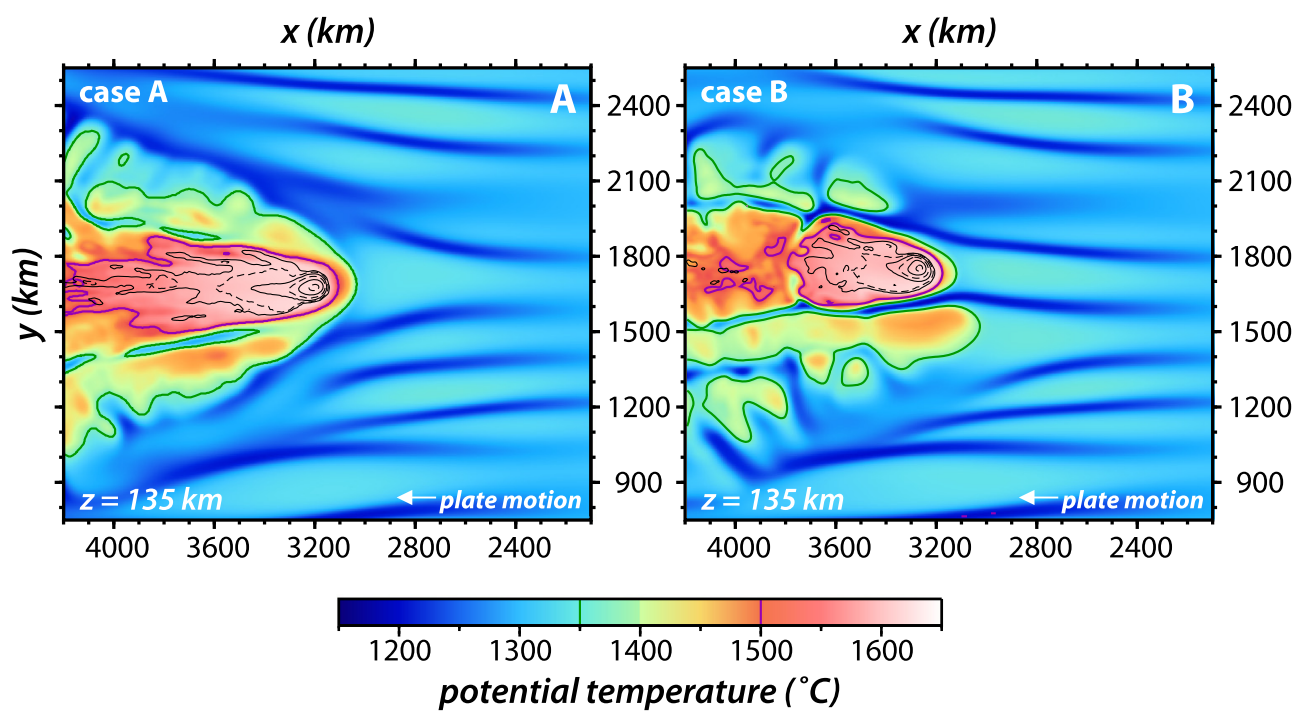

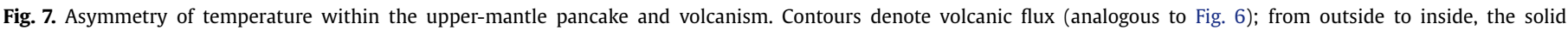

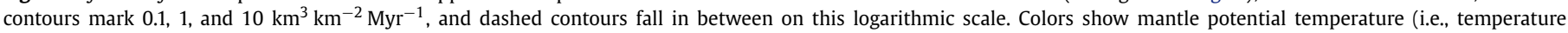

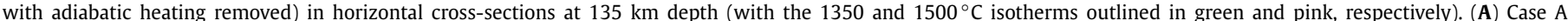

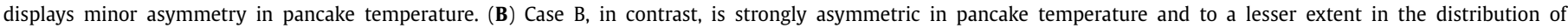
volcanism. (For interpretation of the colors in this figure, the reader is referred to the web version of this article.)

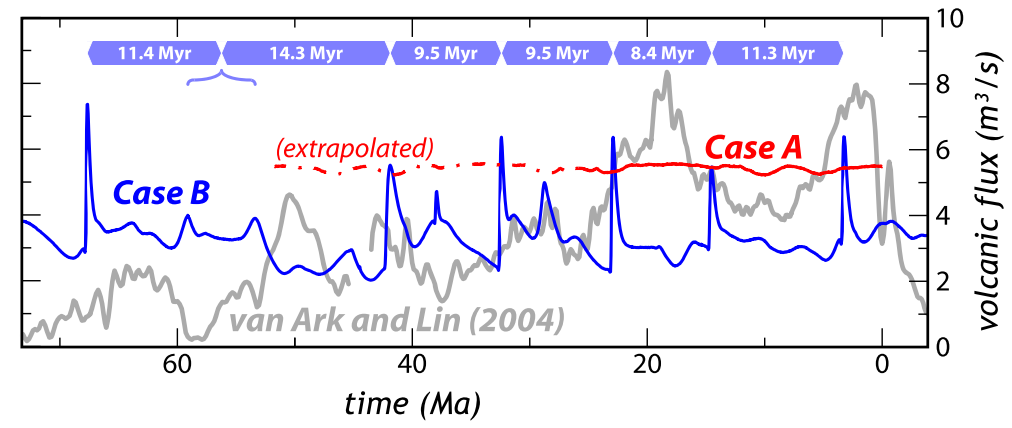

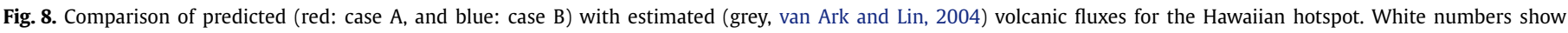
the spacing of the major volcanic peaks predicted by case $B$.

On a more detailed level, trends in major-element versus isotope-ratio space have been interpreted as evidence for the presence of a second mafic component in the source, in addition to the pyroxenitic and peridotitic components modeled (Jackson et al., 2012). Such a more complex source composition is supported by the distinct slopes of the different volcanoes' trends in ${ }^{208} \mathrm{~Pb} /{ }^{204} \mathrm{~Pb}$ versus ${ }^{206} \mathrm{~Pb} /{ }^{204} \mathrm{~Pb}$ (Weis et al., 2011). Whether the data require the distribution of two independent mafic components to be bilaterally asymmetric even in the conduit of a thermochemical plume that is rising with a complex, asymmetric form such as our models predict remains to be tested. The answer is likely to depend on the (as yet unknown) difference in their melting behaviors. Understanding the origin of geographical variations in lava composition is indeed essential to map out first-order compositional structures in the deep mantle (cf. Huang et al., 2011; Weis et al., 2011).

\section{Comparison with seismic models}

Finally, we investigated how the double layering of a thermochemical plume would affect the seismic velocity anomalies resolved by regional tomography. To do so, we predicted synthetic shear-wave velocities from case A. In computing a first synthetic, we focused on the effects of temperature on seismic velocity (Faul and Jackson, 2005), because such dependence is better understood than the effects of composition or melt. A second synthetic
(Fig. 9A) includes the effects of eclogite on seismic velocities [according to Xu et al. (2008), cf. Table S1]. Seismic resolution tests [as described by Wolfe et al. (2009), cf. Supplementary material] were performed for these two synthetic structures to create images that can be compared directly with shear-wave velocity models determined from the inversion of actual seismic data (Fig. 2). For benchmark purposes, we repeated the resolution test for a synthetic structure derived from a classical thermal plume model. (Ballmer et al., 2011) (Fig. 9B). We note that the two geodynamic plume models (thermal and thermochemical) have different plume radii but similar buoyancy fluxes to closely match the most robust observations at Hawaii (e.g., swell dimensions and volcanic flux), an important prerequisite for comparison with each other and with seismic data.

Visual comparison of the resolution tests lends credibility to our thermochemical plume models. The predicted double layering of plume material is not expected to be resolved by the current body-wave inversions; vertical smearing produces a single, broad low-velocity body with a thickness that is comparable to that imaged by regional tomography (Fig. 2), independent of whether (Fig. 9C) or not (not shown) the effects of eclogite on seismic velocities were considered [both these images are visually almost indistinguishable; hence, our interpretations do not critically depend on the poorly constrained effects of eclogite on seismic velocities (cf. Connolly and Kerrick, 2002)]. The single-layer, classical thermal plume is instead predicted to be imaged as a much less pro- 


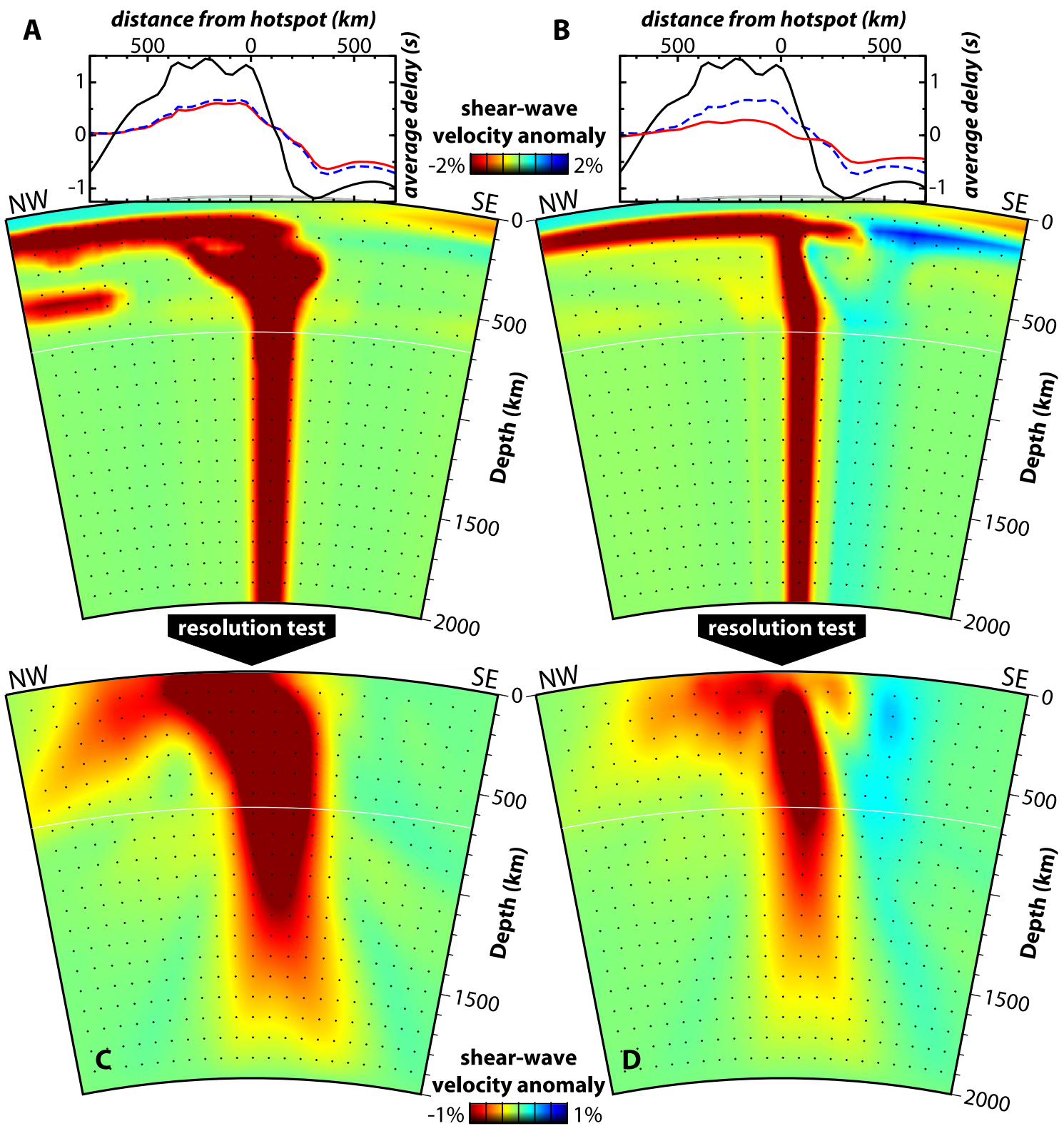

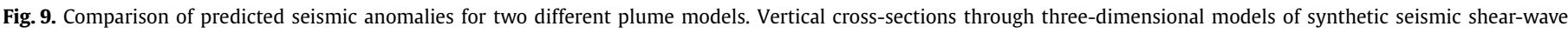

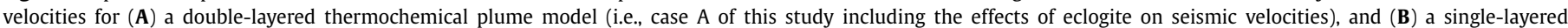

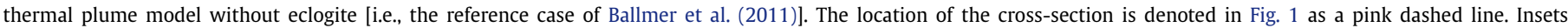

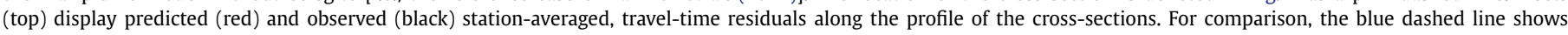

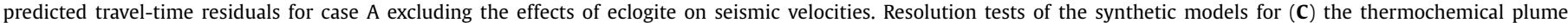

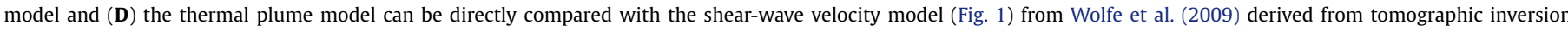

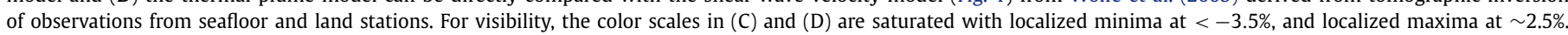
(For interpretation of the colors in this figure, the reader is referred to the web version of this article.)

nounced low-velocity body in the upper mantle, in terms of its overall size, particularly its width at the characteristic depths of the DEP, as well as the maximum velocity anomaly in the shallowest $400 \mathrm{~km}$ (Fig. 9D). Also, in all predicted seismic models, the low-velocity body is surrounded on three sides by a high-velocity curtain made of downwelling material from the base of the lithosphere. This material is more apparent in Fig. 9D (thermal plume) than in Fig. 9C (thermochemical plume) as an artifact of the location of the cross-sections relative to the coolest (fastest) portion of the downwellings.

That the seismic data can indeed better be matched by the thermochemical plume model is also well illustrated by quantitative comparison of station-averaged travel-time residuals (insets in Figs. 9A-B). The observed and predicted residuals are directly computed from the data and the synthetics, respectively, thereby excluding any potential bias from the distribution of sources and stations, or the inversion process. The travel-time residuals are an integrative quantity of the thickness and velocity anomaly of the seismic structure underlying each station. The total variation of $\sim 2.52 \mathrm{~s}$ (peak to peak) in the observed residuals (Wolfe et al., 2009) is better matched by the thermochemical plume model $(\sim 1.24 \mathrm{~s}$ and $\sim 1.40 \mathrm{~s}$ with and without the effects of eclogite on seismic velocities, respectively) than by the thermal plume model $(\sim 0.81 \mathrm{~s})$, once note is taken that the effects of melt and volatile content are not included. These effects should add to the variation predicted in both cases, but more so for the thermochemical plume model, because eclogitic melts can be stabilized up to much higher porosities (10-15\%) and over greater depth ranges than 
peridotitic melts (Yasuda et al., 1994; Yaxley and Green, 1998; Spandler et al., 2008; Mallik and Dasgupta, 2012). Abundance of deep eclogitic melts, stabilized at depths of 150-250 km, would increase the travel-time residuals and expand the apparent thickness of the predicted low-velocity body. Independent seismic evidence for a widespread thermal anomaly much like that of the predicted DEP has come from a recent receiver-function study that images a broad depression of the $410 \mathrm{~km}$ discontinuity beneath the Hawaiian swell (Huckfeldt et al., 2013).

\section{Discussion and conclusion}

This study characterizes the dynamics of an eclogite-bearing thermochemical plume, and by comparing model predictions to observations, provides evidence for such a plume beneath the Hawaiian hotspot. The rise of a thermochemical plume out of a near-neutrally buoyant layer in the mid upper mantle (i.e., the DEP) can give a self-consistent explanation for the asymmetric and time-dependent nature of the Hawaiian hotspot as documented in seafloor topography across the swell (Fig. 1) and crustal thickness variations along the chain (van Ark and Lin, 2004; Vidal and Bonneville, 2004), respectively. As revealed by our resolution tests, a single upper-mantle pancake layer from a classical thermal plume occupies a volume that is too small to explain seismic constraints, whereas thermochemical convection can stabilize greater volumes of hot plume material in the upper mantle. Finally, the asymmetric character of a double-layered plume offers alternative explanations for geographical variations in lava chemistry such as the Loa and Kea trends.

Other studies of mantle tomography and convection on a global scale have shown that hot and compositionally dense layers are present in the lower mantle and can markedly affect Earth's interior evolution (Nakagawa and Tackley, 2005; Labrosse et al., 2007; Garnero and McNamara, 2008; Deschamps et al., 2011). Our work reveals evidence for entrainment and transport of these dense materials by mantle plumes. Probably the most critical episode in the successful ascent of a thermochemical plume from its deep, lower-mantle source to the base of the lithosphere is its crossing through the narrow depth range of about $300-410 \mathrm{~km}$, where the negative buoyancy of mafic materials peaks due to the effects of phase transitions (Aoki and Takahashi, 2004). Less critical may instead be the passage through the thick lower-mantle shell, in which the negative buoyancy decreases with increasing depth, as mafic materials are less compressible than ambient-mantle pyrolite (cf. Samuel and Bercovici, 2006). Thus, it may be the passage through the upper mantle that limits the content of mafic materials that can appear in the source of hotspot volcanism. Like Hawaii, other hotspots may be underlain by thermochemical upwellings, and identifying their geochemical and geophysical surface expressions will improve our understanding of heat and chemical transport through the mantle.

\section{Acknowledgements}

We thank the editor for guidance, and we are grateful to $\mathrm{H}$. Samuel and an anonymous reviewer for valuable comments that improved the paper. M.D.B. has been supported by the Swiss National Science Foundation (PBEZP2-127810) and NSF (grants OCE-00-02819 and EAR-1141938). G.I. has been funded by NSF grant 0855814 and EAR-1141938. Calculations were done at NSF's TeraGrid (XSEDE) using allocation TG-EAR120012, and the Hawaii Open Supercomputing Center. This is SOEST contribution \#8957.

\section{Appendix A. Supplementary material}

Supplementary material related to this article can be found online at http://dx.doi.org/10.1016/j.epsl.2013.06.022.

\section{References}

Abouchami, W., Hofmann, A.W., Galer, S.J.G., Frey, F.A., Eisele, J., Feigenson, M., 2005. Lead isotopes reveal bilateral asymmetry and vertical continuity in the Hawaiian mantle plume. Nature 434, 851-856.

Aoki, I., Takahashi, E., 2004. Density of MORB eclogite in the upper mantle. Phys. Earth Planet. Inter. 143, 129-143.

Ballmer, M.D., Ito, G., van Hunen, J., Tackley, P.J., 2011. Spatial and temporal variability in Hawaiian hotspot volcanism induced by small-scale convection. Nat. Geosci. 4, 457-460.

Bianco, T.A., Ito, G., van Hunen, J., Ballmer, M.D., Mahoney, J.J., 2011. Geochemical variations at intraplate hot spots caused by variable melting of a veined mantle plume. Geochem. Geophys. Geosyst. 12, http://dx.doi.org/10. 1029/2011GC003658.

Connolly, J.A.D., Kerrick, D.M., 2002. Metamorphic controls on seismic velocity of subducted oceanic crust at 100-250 km depth. Earth Planet. Sci. Lett. 204, 61-74.

Crosby, A.G., McKenzie, D., 2009. An analysis of young ocean depth, gravity and global residual topography. Geophys. J. Int. 178, 1198-1219.

Davaille, A., 1999. Simultaneous generation of hotspots and superswells by convection in a heterogeneous planetary mantle. Nature 402, 756-760.

Deschamps, F., Kaminski, E., Tackley, P.J., 2011. A deep mantle origin for the primitive signature of ocean island basalt. Nat. Geosci. 4, 879-882.

Dixon, J., Clague, D.A., Cousens, B., Monsalve, M.L., Uhl, J., 2008. Carbonatite and silicate melt metasomatism of the mantle surrounding the Hawaiian plume: Evidence from volatiles, trace elements, and radiogenic isotopes in rejuvenatedstage lavas from Niihau, Hawaii. Geochem. Geophys. Geosyst. 9, Q09005, http://dx.doi.org/10.1029/2008GC002076.

Farnetani, C.G., Hofmann, A.W., 2009. Dynamics and internal structure of a lower mantle plume conduit. Earth Planet. Sci. Lett. 282, 314-322.

Farnetani, C.G., Samuel, H., 2005. Beyond the thermal plume paradigm. Geophys. Res. Lett. 32, L07311, http://dx.doi.org/10.1029/2005GL022360.

Faul, U.H., Jackson, I., 2005. The seismological signature of temperature and grain size variations in the upper mantle. Earth Planet. Sci. Lett. 234, 119-134.

Fekiacova, Z., Abouchami, W., Galer, S.J.G., Garcia, M.O., Hofmann, A.W., 2007. Origin and temporal evolution of Ko'olau Volcano, Hawai'i: Inferences from isotope data on the Ko'olau Scientific Drilling Project (KSDP), the Honolulu Volcanics and ODP Site 843. Earth Planet. Sci. Lett. 261, 65-83.

Garnero, E.J., McNamara, A.K., 2008. Structure and dynamics of Earth's lower mantle. Science 320, 626-628.

Greene, A.R., Garcia, M.O., Weis, D., Ito, G., Kuga, M., Robinson, J., Yamasaki, S., 2010. Low-productivity Hawaiian volcanism between Kaua'i and O'ahu. Geochem. Geophys. Geosyst. 11, Q0AC08, http://dx.doi.org/10.1029/2010GC003233.

Hanyu, T., Clague, D.A., Kaneoka, I., Dunai, T.J., Davies, G.R., 2005. Noble gas systematics of submarine alkalic lavas near the Hawaiian hotspot. Chem. Geol. 214, 135-155.

Hauri, E.H., 1996. Major element variability in the Hawaiian mantle plume. Nature 382, 415-419.

Herzberg, C., 2011. Identification of source lithology in the Hawaiian and Canary Islands: implications for origins. J. Petrol. 52, 113-146.

Herzberg, C., Asimow, P.D., Arndt, N., Niu, Y.L., Lesher, C.M., Fitton, J.G., Cheadle, M.J., Saunders, A.D., 2007. Temperatures in ambient mantle and plumes: Constraints from basalts, picrites, and komatiites. Geochem. Geophys. Geosyst. 8, 34, http://dx.doi.org/10.1029/2006GC001390.

Hirose, K., 2002. Phase transitions in pyrolitic mantle around 670-km depth: Implications for upwelling of plumes from the lower mantle. J. Geophys. Res. 107, http://dx.doi.org/10.1029/2001JB000597.

Hirschmann, M.M., 2000. Mantle solidus: Experimental constraints and the effects of peridotite composition. Geochem. Geophys. Geosyst. 1, http://dx.doi.org/10. 1029/2000GC000070.

Hirth, G., Kohlstedt, D.L., 1996. Water in the oceanic upper mantle - Implications for rheology, melt extraction and the evolution of the lithosphere. Earth Planet. Sci. Lett. 144, 93-108.

Huang, S., Hall, P.S., Jackson, M.G., 2011. Geochemical zoning of volcanic chains associated with Pacific hotspots. Nat. Geosci. 4, 874-878.

Huckfeldt, M., Courtier, A.M., Leahy, G.M., 2013. Implications for the origin of Hawaiian volcanism from a converted wave analysis of the mantle transition zone. Earth Planet. Sci. Lett..

Jackson, M.G., Weis, D., Huang, S., 2012. Major element variations in Hawaiian shield lavas: Source features and perspectives from global ocean island basalt (OIB) systematics. Geochem. Geophys. Geosyst. Q09009, http://dx.doi.org/10.1029/ 2012GC004268.

Karato, S., 1986. Does partial melting reduce the creep strength of the upper mantle. Nature 319, 309-310.

Karato, S., Wu, P., 1993. Rheology of the upper mantle - a synthesis. Science 260, 771-778.

Katz, R.F., Rudge, J.F., 2011. The energetics of melting fertile heterogeneities within the depleted mantle. Geochem. Geophys. Geosyst. 12, http://dx.doi.org/10. 1029/2011GC003834. 
Katz, R.F., Spiegelman, M., Langmuir, C.H., 2003. A new parameterization of hydrous mantle melting. Geochem. Geophys. Geosyst. 4, 1073, http://dx.doi.org/10. 1029/2002GC000433.

Kohlstedt, D.L., Zimmerman, M.E., 1996. Rheology of partially molten mantle rocks. Annu. Rev. Earth Planet. Sci. 24, 41-62.

Kumagai, I., Davaille, A., Kurita, K., Stutzmann, E., 2008. Mantle plumes: Thin, fat, successful, or failing? Constraints to explain hot spot volcanism through time and space. Geophys. Res. Lett. 35, L16301, http://dx.doi.org/10. 1029/2008GL035079.

Labrosse, S., Hernlund, J.W., Coltice, N., 2007. A crystallizing dense magma ocean at the base of the Earth's mantle. Nature 450, 866-869.

Laske, G., Markee, A., Orcutt, J.A., Wolfe, C.J., Collins, J.A., Solomon, S.C., Detrick, R.S. Bercovici, D., Hauri, E.H., 2011. Asymmetric shallow mantle structure beneath the Hawaiian Swell - Evidence from Rayleigh waves recorded by the PLUME network. Geophys. J. Int. 187, 1725-1742.

Lin, S.C., van Keken, P.E., 2005. Multiple volcanic episodes of flood basalts caused by thermochemical mantle plumes. Nature 436, 250-252.

Mallik, A., Dasgupta, R., 2012. Reaction between MORB-eclogite derived melts and fertile peridotite and generation of ocean island basalts. Earth Planet. Sci. Lett. 329, 97-108.

Moresi, L., Zhong, S., Gurnis, M., 1996. The accuracy of finite element solutions of Stokes' flow with strongly varying viscosity. Phys. Earth Planet. Inter. 97, 83-94.

Morgan, W.J., 1972. Plate motions and deep mantle convection. In: Geol. Soc. Am. Memoir, vol. 132, pp. 7-22.

Nakagawa, T., Tackley, P.J., 2005. Deep mantle heat flow and thermal evolution of Earth's core in thermo-chemical multiphase models of mantle convection. Geochem. Geophys. Geosyst. 6, Q08003, http://dx.doi.org/10. 1029/2005GC000967.

Pertermann, M., Hirschmann, M.M., 2003. Partial melting experiments on a MORBlike pyroxenite between 2 and $3 \mathrm{GPa}$ : Constraints on the presence of pyroxenite in basalt source regions from solidus location and melting rate. J. Geophys. Res. 108, 2125, http://dx.doi.org/10.1029/2000JB000118.

Pietruszka, A.J., Norman, M.D., Garcia, M.O., Marske, J.P., Burns, D.H., 2013. Chemical heterogeneity in the Hawaiian mantle plume from the alteration and dehydration of recycled oceanic crust. Earth Planet. Sci. Lett. 361, 298-309.

Ribe, N.M., Christensen, U.R., 1994. Three-dimensional modeling of plumelithosphere interaction. J. Geophys. Res. 99, 669-682.

Ribe, N.M., Christensen, U.R., 1999. The dynamical origin of Hawaiian volcanism Earth Planet. Sci. Lett. 171, 517-531.

Robinson, J.E., Eakins, B.W., 2006. Calculated volumes of individual shield volcanoes at the young end of the Hawaiian Ridge. J. Volcanol. Geotherm. Res. 151, 309-317.

Samuel, H., Bercovici, D., 2006. Oscillating and stagnating plumes in the Earth's lower mantle. Earth Planet. Sci. Lett. 248, 90-105.

Schutt, D.L., Lesher, C.E., 2006. Effects of melt depletion on the density and seismic velocity of garnet and spinel lherzolite. J. Geophys. Res. 111, B05401, http://dx.doi.org/10.1029/2003JB002950.

Sleep, N.H., 1990. Hotspots and mantle plumes - some phenomenology. J. Geophys. Res. 95, 6715-6736.

Sobolev, A.V., Hofmann, A.W., Kuzmin, D.V., Yaxley, G.M., Arndt, N.T., Chung, S.L., Danyushevsky, L.V., Elliott, T., Frey, F.A., Garcia, M.O., Gurenko, A.A., Kamenetsky,
V.S., Kerr, A.C., Krivolutskaya, N.A., Matvienkov, V.V., Nikogosian, I.K., Rocholl, A. Sigurdsson, I.A., Sushchevskaya, N.M., Teklay, M., 2007. The amount of recycled crust in sources of mantle-derived melts. Science 316, 412-417.

Sobolev, A.V., Hofmann, A.W., Sobolev, S.V., Nikogosian, I.K., 2005. An olivine-free mantle source of Hawaiian shield basalts. Nature 434, 590-597.

Sobolev, S.V., Sobolev, A.V., Kuzmin, D.V., Krivolutskaya, N.A., Petrunin, A.G., Arndt, N.T., Radko, V.A., Vasiliev, Y.R., 2011. Linking mantle plumes, large igneous provinces and environmental catastrophes. Nature 477, 312-316.

Spandler, C., Yaxley, G., Green, D.H., Rosenthal, A., 2008. Phase relations and melting of anhydrous K-bearing eclogite from 1200 to 1600 degrees $C$ and 3 to $5 \mathrm{GPa}$. J. Petrol. 49, 771-795.

Stracke, A., Snow, J.E., Hellebrand, E., von der Handt, A., Bourdon, B., Birbaum, K. Günther, D., 2011. Abyssal peridotite Hf isotopes identify extreme mantle depletion. Earth Planet. Sci. Lett. 308, 359-368.

Tosi, N., Yuen, D.A., 2011. Bent-shaped plumes and horizontal channel flow beneath the $660 \mathrm{~km}$ discontinuity. Earth Planet. Sci. Lett. 312, 348-359.

van Ark, E., Lin, J., 2004. Time variation in igneous volume flux of the HawaiiEmperor hot spot seamount chain. J. Geophys. Res. 109, B11401, http:// dx.doi.org/10.1029/2003JB002949.

van Hunen, J., Zhong, S.J., Shapiro, N.M., Ritzwoller, M.H., 2005. New evidence for dislocation creep from 3-D geodynamic modeling of the Pacific upper mantle structure. Earth Planet. Sci. Lett. 238, 146-155.

Vidal, V., Bonneville, A., 2004. Variations of the Hawaiian hot spot activity revealed by variations in the magma production rate. J. Geophys. Res. 109, B03104 http://dx.doi.org/10.1029/2003JB002559.

Weis, D., Garcia, M.O., Rhodes, J.M., Jellinek, M., Scoates, J.S., 2011. Role of the deep mantle in generating the compositional asymmetry of the Hawaiian mantle plume. Nat. Geosci. 4, 831-838.

Wessel, P., 1993. Observational constraints on models of the Hawaiian hot-spot swell. J. Geophys. Res. 98, 16095-16104.

Wolfe, C.J., Solomon, S.C., Laske, G., Collins, J.A., Detrick, R.S., Orcutt, J.A., Bercovici, D., Hauri, E.H., 2009. Mantle shear-wave velocity structure beneath the Hawaiian hot spot. Science 326, 1388-1390.

Wolfe, C.J., Solomon, S.C., Laske, G., Collins, J.A., Detrick, R.S., Orcutt, J.A., Bercovici, D., Hauri, E.H., 2011. Mantle P-wave velocity structure beneath the Hawaiian hotspot. Earth Planet. Sci. Lett. 303, 267-280.

Xu, W., Lithgow-Bertelloni, C., Stixrude, L., Ritsema, J., 2008. The effect of bulk composition and temperature on mantle seismic structure. Earth Planet. Sci. Lett. 275, 70-79.

Yang, H.J., Frey, F.A., Clague, D.A., 2003. Constraints on the source components of lavas forming the Hawaiian North Arch and Honolulu volcanics. J. Petrol. 44, 603-627.

Yasuda, A., Fujii, T., Kurita, K., 1994. Melting phase-relations of an anhydrous midocean ridge basalt from 3 to $20 \mathrm{GPa}$ - Implications for the behavior of subducted oceanic-crust in the mantle. J. Geophys. Res. 99, 9401-9414.

Yaxley, G.M., Green, D.H., 1998. Reactions between eclogite and peridotite: Mantle refertilisation by subduction of oceanic crust. Schweiz. Mineral. Petrogr. Mitt. 78, 243-255.

Zou, H.B., 1998. Trace element fractionation during modal and nonmodal dynamic melting and open-system melting: A mathematical treatment. Geochim. Cosmochim. Acta 62, 1937-1945. 